\title{
Nay or Jain Nyay 2: Logic of Atheism of Jain Dharm
}

\author{
Mahendra Kumar Jain, Agam Jain \\ University of Delaware
}

\begin{abstract}
Ethos and logos of the Jain thought and practice (world view) is based on reality perceived by senses. Atheistic roots of Jain Dharm have nourished growth, maintained viability and vitality, and kept it relevant for over the last five millennia. Unlike Judeo-Christian-Islam or Brahminical faith, it does not rely on omniscient supreme or god. Its atheistic and anti-theistic thrust is generally known, yet its followers do not call themselves Nastik (non-believers). They emphasize action-consequence relations as guide for successful behaviors with ethical conduct. The basis of their arguments follows from the Jain logic (Saptbhangi Syad Nay) of evidence based inference with multiple orthogonal affirmed assertions (Jain 2011). It conserves information by acknowledging the remaining doubt in an inference. It does not assume binary complementation to force closure for deduction with incomplete knowledge which leads to self-reference and loss of information. This approach offers a rational and practical alternative to conundrum of western atheism even though its arguments are logical and consistent with available evidence. It also obviates need to extract religious morality from social mores. Objective truth and knowledge of established generalizations is necessary but not sufficient for subjective searches to shape desires and for what the future ought to be.
\end{abstract}

Keywords: Atheism, Mahaveer (Mahavira), Jainism, Jains, Omniscience, Nay, Jain Nyay, Nyaya, Tirthankar, Arhat, Arihant, conflict resolution, nonviolence, truthfulness, Buddha (Buddh), nothingness (Shoonyata), limitations of binary logic, logic of inference, Saptbhangi Syad Nay

\section{Introduction}

Vardhman Mahaveer (Vardhamana Mahavira, Mahāvīra 599-527 BC) revitalized the Jain Dharm (Jain 1974c; Shastri 1980) with proscriptions and prescriptions that pave the way to search for the meaning and significance of world happenings accessed from sense experiences. Its path for being to becoming through human efforts follows from the empiricism of seeing for yourself and learning from the experience with equanimity and without expectation (Jain 1974b, 1975; Lalwani 1991). It is based on the assumption that the sense experience of the world (in front of eyes) is interpreted behind the eyes (mind). The external reality is what it is but it is never contradictory. Interpretations of its sense experience and inferences may be fallible and subject to revision. Barren ideas do not evolve, whereas knowledge rooted in reality grows like a vine wherever they find light, support, and nutrition. Successful behaviors based on valid inferences from sense experience guide self with a sense of purpose towards realizing potential for perfection of identity $(\mathrm{atm})$. This atheistic path founded on insistence on reality (truth) and nonviolence to empower individuals with courage for ethical

Mahendra Kumar Jain, emeritus professor, Department of Chemistry and Biochemistry, University of Delaware, USA; main research fields: 2D-Interfacial Catalysis and Logic of Doubt in Evidence-Based Inference. Email: mkjain@udel.edu.

Agam Jain, summer research assistant (2008), University of Delaware, USA; main research fields: Mechanical Engineering. Email: agamjain@verizon.net. 
conduct. It brings clarity to convictions, strengthens commitment to act, and addresses concerns of conscience in personal and social behaviors. On the other hand, truth and intellectual honesty are the first victims of violence, trauma, rape, secrecy, propaganda, ad hoc beliefs, fear, terror, war, and subjugation. Such assaults distort sense of self and fragment identity of victims, and undermine confidence in civil society.

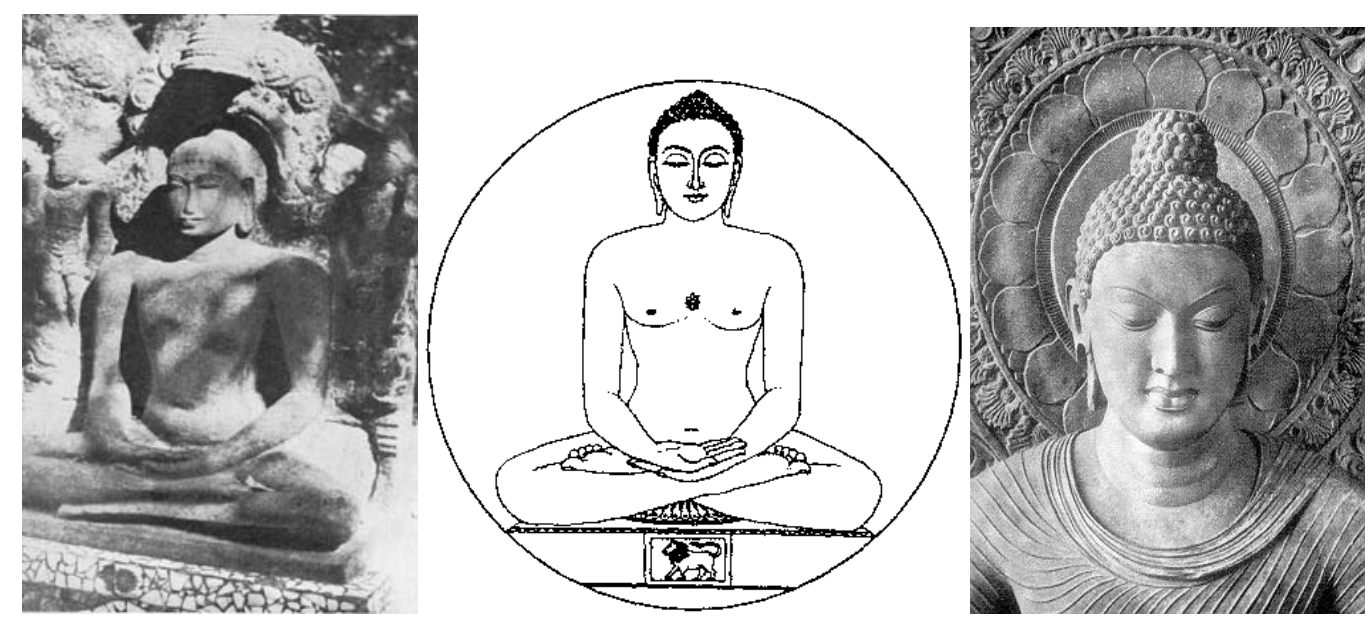

Fig. 1. Images of Jain Tirthankar (left and middle) and Buddha (right). Just as individuals are identified by external symbols, (middle) the symbol for Mahaveer is a lion.

\subsection{The Human Organism}

The world view of Mahaveer at the foundation of the Jain Dharm is based on the assumption that each living organism (jeev) responds to its sense experiences to address needs, and bears consequences of its actions. Organisms survive and thrive by realizing their inherited potential in environmental niches. They learn from feedback to change behaviors and adapt to available resources and deal with threats. Humans as social beings collectively realize potential as forager, tool maker, tinkerer, inventor, and much more. As objective measures, such achievements of the past have unquestionably done more to improve human condition than any faith or ad hoc belief. Yet for diverse reasons their potential for the future successes and failures elicit subjective fears and desires. We often live in a bubble of such perceived reality that bears only passing resemblance to objective worlds. Human condition is a conundrum of objective is from the past pitted against subjective ought (Hume 1777). Paradoxically, we may be able to assemble an ideal human being long before we agree on what an ideal human being is like. Realizing individual potential by shaping the future requires balancing expectations (raag) from wishes and desires. It is like sculpting a rock that requires skills and vision. Clans and tribes use traditions to shape behaviors through idealizations of idols, models, and heroes (Jung 1955). Four major world views offer ways to wade through such conundrum. The first two empirically sculpt ought for behaviors (Dharm) based on is of sense experience. The other two rely on ad hoc of omniscience to comprehend is and cast ought with tribal mores and religious morality.

The Jin Tirthankars encourage the view that all organisms have latent potential for perfection, and that they aspire to develop qualities and abilities to realize it. Sculptures of the Tirthankars (Fig. 1) express veetraag (equanimity) for objectivity without expectation and judgment. It is a desirable human quality for being to becoming charted with truthfulness and nonviolence. A similar worldview was promoted by Buddh (557-480 BC) born 42 years later as a prince 200 miles away (Arnold 1885; Jain 1948). Statues of Buddh illustrate stages 
of human existence, experience, and quality such as (right) karuna (compassion). The other two major world-views seek grace and judgment of omniscience with faith. After 2000 BC, the Aryan herders and nomads from the north-west of Afghanistan brought the Vedic beliefs to India. Over the next 3000 years, these beliefs morphed into the Hindu Dharm that attributes world happenings (Sansaar) to cosmic omniscience of the ever present Brahm and incarnates (avatar). The Hindu social contract is caste based, where all members are duty bound by their Dharm but a select few have birthright to improve their lot through knowledge. The Judeo-Christian-Islamic faiths also seek subservience guided by strictures, dictates, and commandments of the omniscient Theo (God, Omniscience). Theo is personalized as judgmental and vindictive Moses who delivers wrath on sinners. It is benevolent Son of God in Jesus who forgives and bestows grace on believers. Both promise salvation to the chosen few created in the image of omniscience, endowed with unique qualities, guided by free will, and placed at the center of universe. Throughout the history, such true-believers have been empowered by blind faith and motivated by greed and grab (Diamond 1997; Jain 1998) or whatever else (Moore 2004) that gives meaning to meaningless lives (Hedges 2002), including havoc of holy wars, crusades, and colonialism. Not only the idea of God or omniscience does not add up mathematically (Pualos 2008). Mix of aggression, deception, affection, compassion, empathy, and caring is not unique to gods and humans, but also displayed by animals as traits to serve self-interest in relation tribe (De Waal 2013; Jain 2001a).

\section{Jain Dharm as the Legacy of Rishabhnath}

The founding ideas for the Jain worldview are attributed to Rishabhnath (ca 3000 BC) (Chauthmal 1942; Hastimal 1971; Jain 1974a, 1975; Mahapragya 2002; Roy 1984; Sanghvi 1989). He identified skills (kala), 72 for men and 64 for women, to create value to improve quality of life. These include arts and crafts, agriculture, account-keeping, reading and writing, use of numbers, reasoning and logic, ethics, martial arts, gambling, painting, cooking, dancing, singing, and art of making love. Traditions, incantation (mantra), contemplation, meditation, and yoga are also included, but worship is not. Learning useful skills is a necessary part of upbringing of caring individuals in a settled and organized clan. Rishabhnath, as a clan leader (kulagar), also prescribed punishment for those who were out of line. Increasing severity of punishment as admonishment, public trial, and social exclusion matched the crime. Those who did not change behaviors were asked to leave the tribe (banished), but there was no provision for death penalty.

Skills to improve quality of life and realize potential through human efforts remained the focus of the later Jin monks who also lived in the plains of Ganga and Jamuna rivers in North India (Bhattacharya 1976; Johnson 1951; Lalwani and Begani 1975). In Atharveda (ca. 12th century BC), these monks are mentioned as Nigghant (nirgranth or without clothes and possessions) Arhatta (worthy of respect), vatarashana (clothed with air) and vratya (non-aryan). Buddhist works (ca. 4th century BC) refer to them as arhat or nighant saman. The monks who from time to time developed and innovated ways to revitalize the tradition were acknowledged later by their followers (ca. 4th to 1st century BC) as Tirthankar (Divakar 1970). Mahaveer was anointed as a Jin Arihant (arhant, arhat), and also as the 24th and the last Tirthankar for his ideas and interpretations that remain relevant and continue to serve as milestone for the Jain Dharm.

\subsection{Source Material}

Traditional arguments in support of Jain atheism are summarized in this article without criticism of the alternatives. Considerable body of ancient material has come to light since Herman Jacobi showed pre-Aryan 
origins of Jainism (Hastings 1910). This essay is based on my interpretation of the original texts from the Jain tradition written before $800 \mathrm{AD}$. These works and their English interpretations are available on http://www.Hira-pub.org/. This source material is rooted to the beginnings of the tradition. It was revitalized by Mahaveer, and organized by his gandhars (group leaders) for oral transmission. It is said that the eighth gandhar Bhadrabahu I (ca. $380 \mathrm{BC}$ ) was the last to understand the complete work that fragmented after his death. As suitable writing technologies became available, the fragments were written down after 30 AD. Hand-written copies-of-copies-of-copies (pratilipis) of this material have survived for almost 2000 years in the various collections (for example see http://www.jainpedia.org/home.html). These have served as the source for modern printed texts prepared during the last 150 years (now available at no-cost at http://www.jainlibrary.org/). I have also benefited from recent works by scholars who are likely to be familiar with the Jain ethos and of others who have explored secular themes of human behaviors.

Logical and rational basis of Jain atheisms is widely recognized by secular scholars (Dasgupta 1922; Hiraiynna 1932; Roy 1984). Its origins can be traced to the works of Samantbhadra in 2nd century AD (Mukhtar 1925; 1967; 1977) and the work of Siddhsen Divakar in 5th century (Mukhtar 1965; Sanghvi and Doshi 1923). Haribhadra (Jain 2000c; Suri ca. 500) in the 6th century outlined the six ancient views (darshan) that included Brahm and omniscience. These were also refuted by Akalank in 7th century (Jain 1944; 1970), by Hemchandra in 11th century (Hemchandr(a) 1088-1172) and by Gunratn in 15th century (Jain 2000c). All of these authors acknowledge the origins of this way of reasoning to the Jin monks. Also, the Digambar and Shvetambar Jain laity shuns the term nastik attributed to charvak nastik who proposed that organisms respond to sense inputs (like automatons). Its derogatory and materialistic connotations are similar to those for atheism in the west. The Jain view is that organisms respond to sense inputs, however, perception of the meaning and significance of such external inputs depends on the makeup and experience of each individual organism.

\section{Gifts that Keep on Giving}

The followers of Jin Tirthankars are known as the Jain, a term coined ca. 1035 AD from the earlier term jin-anugami. This leaderless tradition is still inspired by the activist world-view of Mahaveer where you are a Jain if you act and behave like one. Its continuous presence and influence in India over the last 5000 years attests to viability of its ideas and practices. It is a tribute to those who from time to time reorganize, modify, and revitalize the tradition and keep it relevant (Johnson 1951; Lalwani and Begani 1975; Suali 1905; Upadhye 1943). At the end of 20th century, there were about five million Jains among the 1100 million people in India (Lalwani 1997). Its ancient roots are maintained by a few hundred monks and nuns with few possessions. They move about on foot in small groups supported by the local followers who provide shelter and sustenance. As always, they do not seek patronage or official protection, nor do they form organized or centralized groups with vested powers. More often than not they preach and teach what they practice. Their influence comes from the strength of individual character and scholarship to address concerns of laity with whom they remain in touch, listen to their concerns, and advise about the Dharm. They innovate ways to overcome stasis and orthodoxy while the splinter groups explore new ideas.

\subsection{Activism}

Indian school textbooks credit Mahaveer (599-527 BC) as a social activist and reformer of religious and social practices of his time. He is on the list of The 100 Most Influential Persons in History (Hart 1972), yet 
very few people outside India know of Mahaveer (Shastri 1991). His ideas for social change by non-violent means and conflict resolution through discourse remain universally relevant. He opposed discrimination or privilege on the basis of accident of birth (caste, creed, sex, and social order). He used empirical arguments to encourage human efforts (actions, behaviors, relations) to improve condition and quality of life for all organisms. His social contract of live, let live, and thrive acknowledges interdependence of all life forms. It calls for reasoned conversation to resolve conflict and arrive at a rational basis for coexistence because interest of one lies in the interest of all. He prescribed behaviors that seek congruence of actions with words and thought. He encouraged tolerance for ideas unless shown to be detrimental, not relevant, or contradictory. Such empirical reasoning with experienced (observed and measured) reality (sat) supported by independent evidence (praman) also requires insistence on truthfulness (satya).

Open search for viable ideas for rational behaviors is derailed by blinders of faith and ad hoc beliefs. The anti-theistic arguments of Mahaveer are based on the concern that violence, fear, ignorance, indulgence, reflex response, and reptilian behaviors rob ability of senses to see and of mind to think. As a social activist, he argued against ritual practices and questioned their relevance as in if sacrificing an animal is its path to heaven, why not sacrifice own relatives. Beliefs encourage adherence to constructs and practices that may not have demonstrable value. If disease is wreath of god or evil spirits why look for treatments and cures. Imagine what will happen if the head of states and war mongers who declare war were asked to serve in the line of fire.

Mahaveer revitalized the ideas of prior Tirthankars and countered the newly arrived Vedic and Vedantic (post-vedic) beliefs about the role of omniscience or other-worldly Brahm (Bhandari 1982; Bhansali 2001; Jain 1951). He built his arguments with the assumption that each living organism responds to its sense experiences and bears consequences (phal) of its actions (karm). Individuals learn by trial and error from feedback for midcourse corrections. Outcomes and consequences motivate behavior changes that include not only the physical acts but also words and thought that have a common basis in the sense experiences and perceptions that guide decision-choices and responses. Empirical course of rational behaviors tracks coherence of the reasoning ability to access the past experiences and evaluate potential outcomes for consequences. Congruence of thoughts and words with actions is the basis to sculpt identity. Consequences of disconnect between thoughts, words, and actions include psychoses, cognitive dissonance, and fragmentation of identity.

Time Magazine at the end of the 20th century recognized Gandhi as one of the three most influential persons of the century, and the other two are Einstein and Hitler. Mahatma Gandhi credited Jain monks and laity for insights that lead to his nonviolent activism with insistence on truth (Satyagrah) to expose unfairness of entrenched interests (Gandhi 1942). Armed with the belief that a few good people can change the world, Gandhi asked his Satyagrahis to live the change they want to bring, and to let behaviors speak louder than words. His methods for nonviolent political and social change are now generally adopted for human rights, social equality, civil society, openness, and honesty in Government, corruption, and wherever and whenever vigilance and whistle-blowing is called for to expose fox entrusted to protect hen house. King and Mandela may have been at the political forefront, but many more activists, organizers, whistle blowers, and ordinary citizens are guided by their conscience for struggles and movements at their grassroots.

\subsection{Independent Evidence Empowers Reasoning}

Empirical search for reality (sat) by trial and error follows truthfulness (satya) empowered by independent evidence. A valid inference (anuman) from reasoning conforms to parts of reality inherent in the input 
assertions and the relationship of content and context of the actualities (dravya) to independent evidence (Jain 2003; Mukhtar 1965). An inference remains tentative (syad) and in search of additional inputs (anekant) to resolve remaining uncertainties, doubt, and liabilities. The parable of An Elephant and Six Blind Men (Fig. 2) illustrates the dynamics of such reasoning that underlies ethos, pathos, and logos of the Jain world-view. In this parable, each person sees a part of the beast and interprets it on the basis of its own experience. Of course, a better inference follows from the synthesis of such partial views, and additional inputs may lead to a better inference. Conundrum of your word against mine may persist in search of a better inference. What if nobody has seen the beast before? What if somebody invokes omniscience?

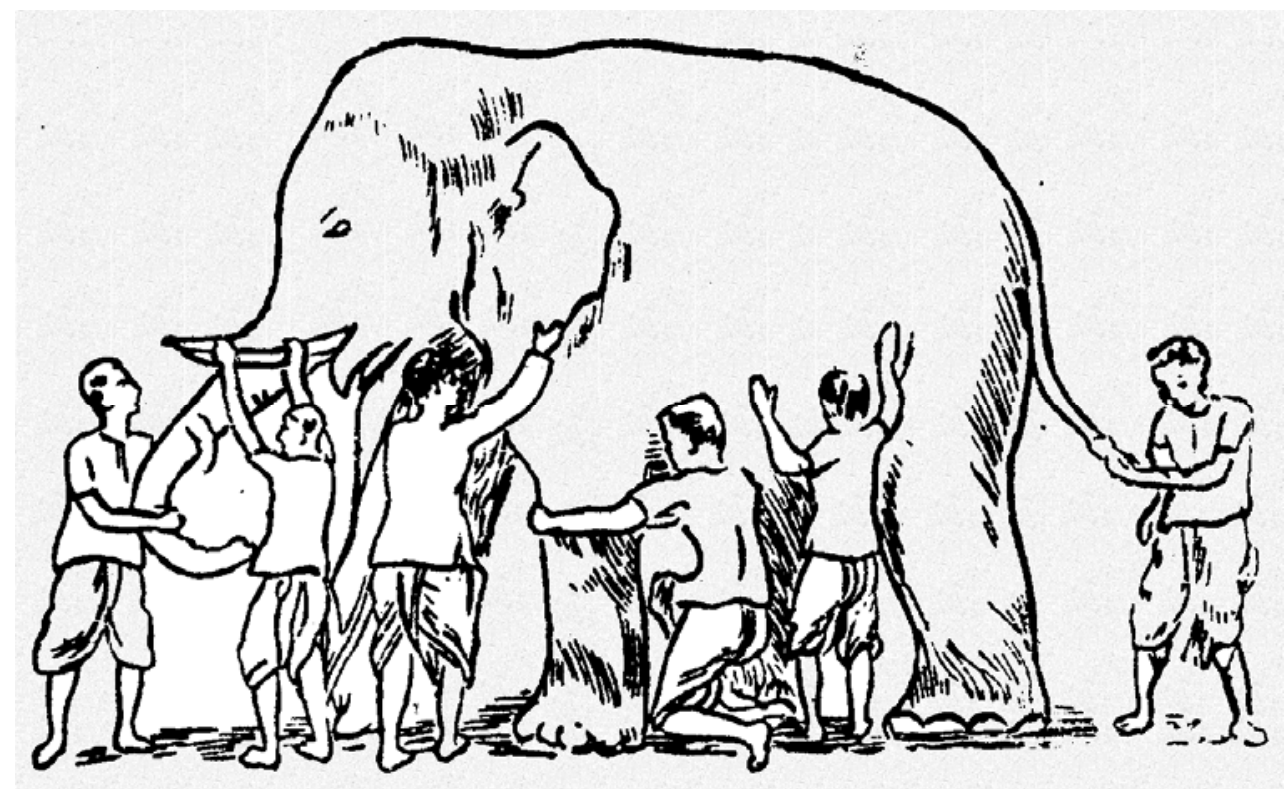

Fig. 2. Six blind men trying to infer identity of the beast.

Word reasoning is about objects that exist independent of the word. Inference evolves by trial and error in search of such information and evidence. Just as a story improves with each retelling, additional inputs continue to improve ideas, technologies, and organizations. Similarly, biological evolution is about reproductive success by trial and error, and survival depends on learning from consequences of actions and behaviors. Empiricism of trial and error also holds for reasoning and learning from the observed and measured facts to develop shared knowledge of what may be "unseen." Word representations allows us to share concerns and infer reality from the communicated content (what, which, who), context (where, when), and their relations (how much, far, large) with independent evidence. Such scrutiny for predictable, reliable, and certain future makes the world less scary.

Successful behaviors are guided by reasoning with evidence-based inferences (Rogers and Jain 1993), and side-tracked by faith in constructs of ad hoc beliefs. Western atheism is a response to the omniscience of Theo (God) and to religiosity of tribal mores that encourage the faithful to be kind to their own and exploit others (Armstrong 1993; Dawkins 2006). Such in-box and self-referential reasoning is also inherent in spiritual, metaphysical, mystical, legal, and political rationalizations. Believers of all shades and stripes have failed to find evidence for objects of their faith, yet they claim that there is no evidence that it does not exist. The nature of evidence is such that the burden of proof for it exists is on those who assert it, and until then no evidence is 
the evidence that it does not. Pascal's wager justifies faith as a bet for being on the right side in case a judgmental God exists. Agony of agnostics is equivocation about such a wager. Open inquiry requires courage to break out of illogical, irrelevant, and ad hoc assumptions, and objective science stops with valid and viable generalizations. What to do with such knowledge is a matter of choice and judgment. Unequivocal rejection of mores of religious morality based on faith in omniscience by atheists is logical. The activism of anti-theists is against religious perniciousness. Such choices encourage individuals to develop a sense of self to sculpt identity with ethical behaviors. It is not rooted in mores and does not require mindless faith in morals. It is not an issue for ad hoc morality.

\subsection{Ethical Conduct and Behaviors Guided by Atheism}

Organisms seek ways to survive and thrive. Mahaveer further emphasized (Muni 1973) that humans can develop rational balance (samma, sammyak) of instincts, emotions, and expectation in behaviors (thought, words and actions). Ability to evaluate consequences and learn from experiences also places responsibility for choices, decisions, and behaviors towards a fair and responsive social order. Discipline and self-restraint (sanyam) in behaviors is called for because actions are not reversed and consequences are not averted.

An anecdote illustrates the path for a beginner. Mahaveer was travelling through a forest. The leader of the forest tribe heard that here is somebody who encourages nonviolent behavior. The thought resonated with him because he was well aware of the toll of violent struggles between and within the forest tribes. He paid a visit to Mahaveer and asked what he could do to bring nonviolence in his life. Mahaveer said that he should start by not eating crows. The Chief replied that of course he does not eat crow because they feast on dead animals. Mahaveer complimented and said that he is well on the path of nonviolence. Now he should decide what he wants to accomplish next. No matter what, when, and where, change begins with behaviors that are sustained, and such successes empower incremental search for what more and how. Self-motivated changes to arrive at the "aha" moment is the crux of teachings of Mahaveer and Buddh as guide to ought of own choosing.

For the beginners, Mahaveer proscribed violence, lying, stealing, illicit relations, and possessions. Awareness of unpleasant, undesirable, and unpredictable outcomes and binding (bandh) consequences of such actions are likely to motivate behavior change (Laham 2012). Punishment is self-inflicted on those who do remain trapped and suffer through action-consequence cycles. As we know, now the list for such slippery slopes includes instinctive, reflexive, reptilian, and addictive behaviors. Consider the personal, social, economic, and medical consequences of addiction to recreational drugs, alcohol, tobacco, narcotics, starvation (fasting, dieting), and also of excessive consumption of foods like meat, milk, fat, and sugar. Sense of self is also distorted by rituals, fashions, gizmos, banter, chatter, sound-bites, propaganda, and other forms of indulgences. Then there are the more insidious influences that encourage and sanction wars and violence that leave lifelong physical and psychological scars on individuals and societies.

\subsection{Identity}

The world-view (itthivay) of Mahaveer encourages incremental qualitative change in behaviors (gunasthan) to develop a sense of purpose and self to perfect identity (atm) to shape future behaviors and address survival and quality of life concerns. The adjective atm distinguishes a living organism that may assert I am, I do, I will, I feel, I think. Sometimes after $200 \mathrm{AD}$, the term morphed it into atma, a noun for spirit or soul with connotation of an independent entity. Atm is the identity that distinguishes an individual from others, 
that is how others see you (bahir-, external, social), how you see yourself (antar-, internal strength of character), and how you will be seen ever after (param-, universal) (Mukhtar and Shastri 1965). Such individuation begins with naming, and soon thereafter children express their goal for example to be a fire-fighter or a teacher. Personal commitment is required to develop sense of self to shape identity, and family and social influences also play a role. It often begins with the realization that enough is enough. Beyond that, flickers of awareness empowered by incremental successes encourage choices and decisions for desired behavior consequences. Such influences go awry in psychopaths and mass murderers.

Prescriptions of Mahaveer to sculpt identity by qualitative change begin with self-restraint on compulsive, obsessive, and indulgent behaviors. According to the ancient literature (Jain 1938, 1939a; Saha 1965), sense of self helps sculpt identity with change in quality perception (gunasthan) in 14 stages. Some animals and most humans learn to respond with external (stage 4) and internal (self-) restraints (stage 5), however only humans can choose a purpose and path to sculpt identity. Mahaveer is said to have attained the last (Ayog Kevali) stage (14th) just before his Nirvan (death). Among the estimated 40,000 inductees in next eight generations of his Original group (Mool Sangh), fewer than 100 reached the 13th stage (Sayog Kevali). Bhadrabahu I (ca. 380 BC) was the last (Kasliwal 1912). After him, the Mool Sangh disintegrated for the lack of a leader of Kevali distinction and also lacked qualities and knowledge for the 12th veetrag stage. As a result, the body of orally transmitted knowledge fragmented and scattered with the splinter groups. What has come down to us as the Jain Agam (knowledge from the past) was assembled from the surviving fragments written down with commentaries during $100 \mathrm{BC}$ to $1000 \mathrm{AD}$. Some of these works retain words and phrases and even the original fragments from which the integrity of the thought process can only be guessed.

\subsection{Action-Consequence Relations}

The Jain worldview follows from the assumption that each organism does (karm) its best to survive and bear consequences (phal) of its actions. Organisms individually and collectively also depend (pajjata) on their environment for food, water, air, movement, interaction, and communication with others. A cohesive and consistent code of conduct therefore takes into consideration wellbeing of all interdependent entities in a finite world.

Mahaveer, during his first visit with Indrabhuti Gautam (607-515 BC), who later became his discussion leader (Muni 1990), explains that a living organism interacts with its environment for survival needs. Inputs and outputs for the action-consequence relations are rooted in the reality of the sense experience of each organism and also the actuality of the environment. Internal images of sense experiences inevitably color perceptions that guide decision-choices to address concerns and shape behaviors. A code of conduct is required to evaluate consequences and liabilities because chances of success increase with behaviors that do not contradict reality, are consistent with what is known to be valid (prior knowledge), and those that avoid actions that are irreversible or inconsistent with goals. Indulgences commit an individual to actions with undesirable consequences, and their feedback may provide for correcting mechanisms (such as avoidance). However, once trapped, there is little choice but to suffer through the action-consequence cycle until it is resolved. A code of conduct guides towards aha moment for a closure (apvarg) forever (mukti, nirvan) without divine judgment or grace for insight.

According to Gautam Sutr (Jain 2000a), action-consequence relations (like correlations) are rooted in the reality (sat), rather than caused by Ishvar (omniscient). Lung cancer is for example correlated to smoking. As 
we know now smoking is one of the causes of lung cancer, non-smokers also develop cancer and not all smokers develop lung cancer. Uncertainties, contingencies, and exceptions associated with outcomes of complex behaviors involve unknown variables. With the caveat that correlation is not causation, inferences based on correlation are useful guide for behaviors. If in doubt, it is prudent to avoid irreversible actions.

\section{Conservation of Reality in Reasoning}

Perhaps the most significant contribution of Gautam and Mahaveer is about reasoning with multiple inputs (anekant) to improve certainty. They suggested that liabilities in reasoning from a single assertion (ekant) are resolved with additional inputs affirmed by independent evidence (praman). Its conceptual basis comes from Rishabhnath:

\section{उप्पानेई वा विगमेई वा धुवेई वा}

i.e., a change in tangible reality (sat) is the net balance of inputs and outputs. Such conservation underlies all insights and thoughts of the Jain tradition. It is more than just you harvest what you sow, or for balancing the account books. It is conservation of information that is not unlike the conservation of materials and energy. As enshrined in laws of thermodynamics and chemical change, it is at the foundation of all sciences and technologies. Balance of inputs and outputs as the basis of action-consequence relations also holds for fungibility of money, investments, tools, rules, accountability, and responsibility for fair and equitable economic and social interactions in a civil society. In all such cases, neither something real is created from nothing, nor real things disappear into nothing. It takes stock of the underlying reality perceived from sense experience. Ultimately, conservation of reality at a conceptual level for reasoning is symbolically represented and manipulated during logical operations and inputs and evidence for outputs.

Mind is trained and programmed to interpret images of external actualities captured from sense inputs and experiences. It also interprets such inputs in relation to independent evidence to draw on attributes of shared reality. Logics track consistency and discard contradictions in a valid inference. As a part of shared knowledge, it grows like a vine nourished with additional inputs and open scrutiny. On the other hand, one gets only what is put in description of a dream. Imaginings of faith find their way into magic bag that takes in everything and gives out anything. Such contradictions and inconsistencies often result from self-reference associated with ad hoc omniscience of a supreme creator, potter, puppeteer (scriptwriter or judge), or designer. Such beliefs create cognitive dissonance with constructs of other-worldly, divine, or wishful as in god-willing and God works in mysterious ways. Nay reasoning encourages practice congruent with thought and words to empirically learn from outcomes and consequences of reasoning, actions, and behaviors. Reality dictates what is done cannot be undone, and it is insanity to expect different outcomes from same inputs or by repeating the same action. Once the arrow leaves the bow, all one can do is to bear the consequences, and learn from the experience, and modify future behaviors if there is a second chance.

It was recognized during the time of the 23 rd Tirthankar Parshvanath (ca. $850 \mathrm{BC}$ ) that conservation is the basis for action-consequence relations as well as the role of independent evidence for Nay reasoning. Mahaveer and Gautam extended, strengthened, and formalized the reasoning to interpret word expressions and assertions about the content and context of identified and meaningful parts perceived from sense experience (Chand 1948; Jain 1944, 1970, 1982; Kondey 1949; Suri 1929). Reasoning with perception of the observed and measured actualities (dravya) builds on following assumptions: (1) External world in front of eyes (pratyakch, subject of 
sense inputs) is what it is and it does what it does. (2) It is neither created from nothing nor does it disappear into nothing. (3) It has always existed and will continue to exist albeit with changes in forms. (4) Its complexity may appear daunting, however it is never contradictory. (5) Images of sense inputs are formed and interpreted behind the eyes (parokch, mind). (6) An organism extracts information from awareness (chetana) of inputs interpreted in relation to its experiences and perceptions. (7) Most of our sense experiences may go un-cognized yet their perceptions (itthi) may persist. (8) Perceptions form beliefs that guide decision choices, actions, and behaviors. (9) Inferences from criteria-based (anugam) reasoning with cognized sense experiences (gyan) are useful to represent, reason, interpret, assert, evaluate, share, and compare experiences. (10) Each organism is a spectator, actor, and decision maker that bears consequences of individual and collective actions that may be life altering, make it happy, or anxious and regretful.

\subsection{Inference from Inputs of Orthogonal Assertions}

Human languages permit communication over large distances and long periods as the word constructs are interpreted to deliberate, reason, share, infer, and scrutinize. Ability to communicate and reason requires bridging the gulf between beliefs, words, and practice. Narratives may build on perceptions of sense experience, however speaking your mind to converse and deliberate to resolve a concern require communication of inferred output from identified inputs. If common sense aligns sense inputs with perceptions, it takes uncommon sense to align outputs with perceptions of inferred and shared realities of phenomenal world. Such scrutiny begins with identified content (what, who) and context (where, when), and their relations (how) and causality (why) for output and consequences. Such open-ended search for certainty proves and improves as some uncertainty goes away with each day. Mahaveer in response to a query from Indrabhuti Gautam emphasized that a belief is inferred not only from the content and context of what one knows and how it came to be known, but for its fuller understanding, it is also necessary to know what one does not know, what else is needed, and what may falsify and contradict it. Such boundaries define realm of Jain Nay.

We assert existence of an object from differing sense inputs from its presence versus its absence. Many of our concerns are about objects that we do not "see" and perceive, or their perceptions are illusory as measures of reality. Shared exploration of an object or concern begins by naming it, which alone does not confer reality. Its identity is sculpted (satprarupana) from affirmed attributes and behaviors. A valid inference (anuman) follows from complementary and orthogonal inputs (Jain 2011) obtained from explorations (margana) for criteria based (anugam) content (dravya) and context (paryaya). Such reasoned inferences remain valid within the limits of inputs and evidence (praman), and its liabilities may be addressed by additional (anekant) inputs (Jain 2003, 1944, 2001b; Mukhtar 1965; Sanghvi and Doshi 1939). The only (keval) and complete (sakal) knowledge (gyan) of an object or concern emerges in stages as the remaining liabilities (doubt, uncertainty, or inconclusiveness) are resolved. Inference of fire from the sight of smoke at a distance may for example be strong enough to warrant further inquiry to suggest presence of fire to be confirmed with additional evidence. Empirical strategies to interpret incomplete knowledge are necessarily chaotic and confusing however provisional inferences remain useful guide for further search and mid-course corrections.

\subsection{Saptbhangi Nay}

In the elephant parable (Fig. 2), an inference constructed from multiple assertions remains tentative. Its liabilities (syad) may be resolved in stages with additional inputs, criteria, methods, and evidence (anekant). 
Search for it is (for an object like omniscience or even the Sun) may begin with what we know about it, and then also consider what we do not know, and whether or not we know or do not know other facts. Each assertion is to be affirmed by independent evidence, and the nature of evidence is such that separate and independent evidence is also required to affirm converse of an assertion.

The Saptbhangi (Jain 2011) Nay syllogism permits eight possible propositions from a set of three assertions which may (+) or may not (-) be affirmed by independent evidence. Such evidence may provide additional information for interpretation and proof, or to rule out alternatives and refute the converse. For example, existence of an object asserted as Asti or it is (A) may be affirmed (+) by sense experience of its observable and measurable attributes. Assertion $(\mathrm{A}+)$ is strengthened if its converse assertion Nasti or it is not is not affirmed ( $\mathrm{N}-)$ by independent evidence. It is challenging to garner evidence to affirm (N-), but it is suggested if consequences of the presence and absence of the object are not distinguishable. Consider ways to establish the existence of air or Sun. Can the same criteria and methods be used for Omniscience said to be present everywhere and forever? It is conceivable that an object present everywhere is beyond the sense experience (A-) and also consequences of its presence or absence cannot be distinguished (N-). If so, can this object be meaningfully described to inform deliberation? If not, it is a-vaktavya or it is undescribable (U+). In contrast, a concern like pain affirmed $\left(\mathrm{A}^{+}\right)$by sense experience is meaningfully described (U-) for further consideration.

Table 1

Propositions with N, A, and U Assertions Affirmed (+) or Not-Affirmed (-) by Evidence

\begin{tabular}{|c|c|c|c|c|}
\hline & $\mathrm{N}$ (does not exist) & A (exists) & $\mathrm{U}$ (un-describable) & bit map \\
\hline 1 & - & - & - & 000 \\
\hline 2 & - & + & - & 010 \\
\hline 3 & - & - & + & 001 \\
\hline 4 & - & + & + & 011 \\
\hline 5 & + & - & - & 100 \\
\hline 6 & + & + & - & 110 \\
\hline 7 & + & - & + & 101 \\
\hline 8 & + & + & + & 111 \\
\hline
\end{tabular}

\subsection{Inference without Evidence: Nothing or Everything?}

An inference proposition is valid within bounds of its evidence. Umaswami (Tatia 1994) noted (प्रमाएनयैंरधिगमः) the authority of an affirmed assertion for reasoning comes from evidence. It may be about a certain aspect of the object as a particular or a class, or its current state or as it was in the past, or a functional state or dormant form. Samantbhadra (Jain 1914; Mukhtar 1925, 1967, 1977) emphasized that a proposition with a single assertion is necessarily incomplete (Mukhtar 1977; Shah 1970). Siddhsen Divakar (ca. $500 \mathrm{AD}$ ) reiterated that reasoning is not possible unless all assertions about the content and context of an object are affirmed by evidence (Mukhtar 1965; Sanghvi and Doshi 1939; Vidyabhusan 1984). Buddhists surmised that nothingness (shoonyata) perceived by getting rid of chatter and clutter in sense inputs is the ultimate state of validity against which all sense experiences are transitory constructs like clouds in the blue of space. Shoonyata in effect is a blank template to represent and interpret sense experiences, just as a blank sheet of paper can be used to write or draw anything one wishes. Akalank (Jain 1939b; 1944) rebutted this construct as self-referential because the state of shoonyata is without a basis in the content and context of an object or 
concern, and it is also without value for reasoning. Hemchandra further emphasized (Suri 1910; Thomas 1968) चिना ममाण परवन्ग रून्य: that is unless supported by independent evidence an assertion is no different than nothing. Evidence based reasoning in defense of Jain atheism was reiterated by Gunratn with the conclusion that reliance on criteria-based assertions affirmed by independent evidence is antidote against omniscience of the binary and ad hoc constructs (Dasgupta 1922; Jain 2000b; Suali 1905).

\subsection{Incarnation of Nay as Jain Nyaya}

At the time of Mahaveer, some 400 different views prevailed about omniscience. Such Upnishadic (800 to $400 \mathrm{BC}$ ) discourses often ended up in conundrum of your word against my word. Bhadrabahu I (ca. 350 BC) emphasized that describable (U-) A and $\mathrm{N}$ assertions give four logic states: it is (T), or it is not (F), or it is both (D), or it is neither (X). These are to be resolved with independent evidence. Hiraiynna (1921) noted that these four syad states challenge the dichotomy of true or false in the faith-based Vedic absolutism, and also identify contradiction of the undifferentiated Upnishadic reality of it is so, and also it is not so (eti eti, neti neti).

The six world-views (Darshans) were predominant in India in sixth century AD (Suali 1905). Atheistic Buddhist and Jain remain independent to this day. Theistic Sankhya, Jaimaniya, Vaisheshik, and Naiyayic who invoked "cause" are assimilated in the present form of Brahminical Hindu Dharm. Their discussions generally followed rules of debate from Gautam Sutr compiled by Ackhapad (ca. 100 BC), and popularized as Nyay Bhasya (commentary) by Vatsyayan (ca 400 AD) (Jha 1939). It is not clear in what form and how the source material for Gautam Sutr came to Akchapad. It is likely that it is the work of Gautam (ca 550 BC), a well-respected mediator of Upnishadic discourses who at the age of 52 joined Mahaveer and became his discussion leader (Muni 1990). The term Nyay for justification and judgment came into use sometimes after 200 AD (Vidyabhusan 1970; 1977), apparently for synthesis of Nay (reasoning for an inference) with Vedantic anvikshi (scrutiny) and Buddhist tark (logical deduction). The term Nyay is not found in the Gautam Sutr, and it appears only once in its Nyay Bhasya (commentary by Vatsyayan ca 400 AD) in a rather insignificant context. The term Nay in Gautam Sutr appears as nir-nay (decision) and up-nay (additional support). The term Nyay came into the Jain works after 800 AD. Emphasis of Jain Nyay or Jain logic on independent evidence (praman) and scrutiny (parikcha) distinguishes it from the Hindu Nyay that invokes scriptures as valid evidence for reasoning. Unfortunately, in recent years, the Jain scholars in their zeal for literal interpretations of the ancient works have lost the significance of the conceptual and logical basis of the Jain Nay.

\subsection{Significance of the Saptbhangi States}

Of the eight $\left(2^{3}\right)$ propositions in the table above with $0,1,2$, or 3 affirmed $(+)$ assertions, seven (saptbhnagi) have truth value of at least one affirmed assertion to provide a basis for reasoning. As mentioned above, the (A+ N- D-) state for affirmed it is $(\mathrm{A}+)$ is neither falsified nor undescribable. The other six states may be interpreted as propositions with inconsistency, contradiction or falsehoods. The eighth with no affirmed assertion (A-, N-, U-, or 0, 0, 0) may be for Shoonyata, omniscience, or indeterminate.

Three assertions (A, N, and $\mathrm{U}$ ) interpreted as three orthogonal basis vectors represent a three-dimensional logic space. In vector-matrix algebra (Ramachandran 1979; 1982; 1983), the eight corners of such cubic space represent eight distinct logic states. Virtually all logics including binary, probability, and Bayesian are the limiting cases of this logic space of a proposition. A logic space can have as many dimensions as the number of orthogonal assertions, and such representations are remarkably useful to interpret meaning of each state. They 
also describe states of quantum phenomena. Its actuality forms the basis for quantum computing whose feasibility has been demonstrated. Its full potential for machine-implementation for inference and decision-making with incomplete information remains to be realized.

\subsection{Syad-Saptbhangi in the Limits of Binary Logic}

Sense inputs provide information about parts of actuality and sense organs communicate such orthogonal information interpreted for a range of inferences. The only (keval) valid inference is thus a point in such multidimensional logic space (anekant) of as many assertion vectors as needed. As shown in Fig. 2, in the 2D logic space of orthogonal $\mathrm{A}$ and $\mathrm{N}$ vectors, $\mathrm{A}+$ is for affirmed it is, and $\mathrm{N}+$ for independently affirmed it is not. Several insights emerge if orthogonal $\mathrm{A}+$ and $\mathrm{N}+$ are approximated as $\mathrm{T}$ and $\mathrm{F}$ of the classical logic: (a) Complementation of $\mathrm{T}$ and $\mathrm{F}$ (as $\mathrm{T}=$ not- $\mathrm{F}$, and $\mathrm{F}=$ not- $\mathrm{T}$ ) is an approximation at the two ends of the $\mathrm{T}-\mathrm{F}$ diagonal line. (b) The T-F line also describes the range of classical probabilities of 1 (T) and 0 (F). (c) Two additional states are also apparent: doubtful (D) for both $\mathrm{T}$ and F, and node or null (X) for indeterminate neither T nor F. (d) Representation of $\mathrm{T}$ and $\mathrm{F}$ as orthogonal vectors oin 2D-logic space circumvents self-reference paradoxes of binary deduction $\mathrm{T}=$ not-T. The Liar paradox of All that I say is lie implies self-reference resulting in deduction of true is not-true.

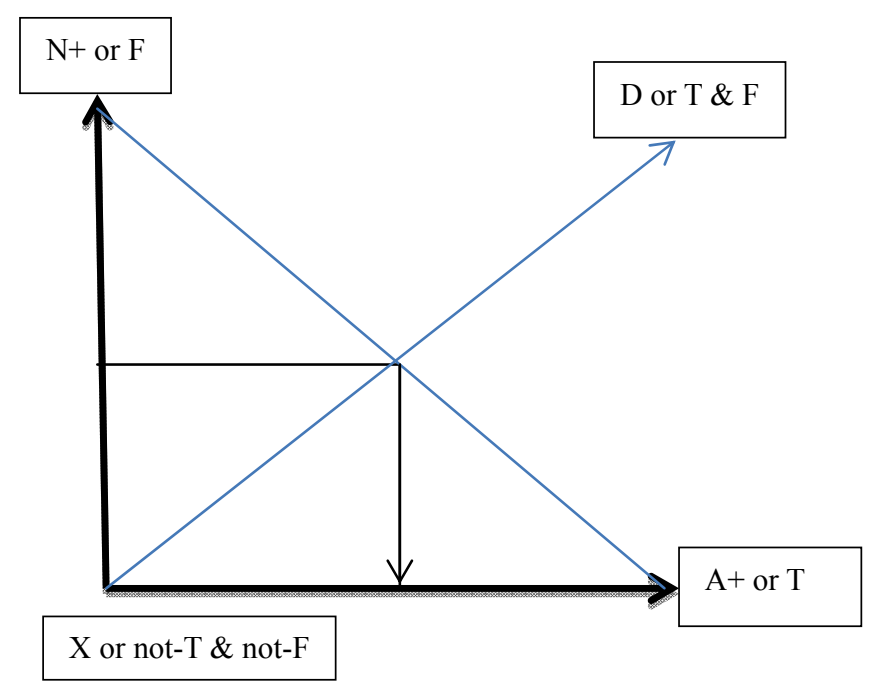

Fig. 3. Representation of two orthogonal assertion vectors $(A+, N+)$ to generate other states such as True (T) and False (F) and also Null (X) and Doubtful (D).

Complementation of $\mathrm{T}(1)$ and $\mathrm{F}(0)$ for binary deduction permits closure condition necessary for deductions and mathematical proofs (Suppes 1957) has also detoured Western logic into various forms of self-reference that lead to vicious circles, riddles, paradoxes, perpetual motion machines, and omniscience. In binary, reasoning a proposition is said to be true $(\mathrm{T})$ if it satisfies a particular criteria, and it is false $(\mathrm{F})$ if the criteria for $\mathrm{T}$ are not met. In effect, $\mathrm{T}$ and $\mathrm{F}$ states are inferred on the basis of one piece of evidence (say $\mathrm{T}$ ), and $\mathrm{F}$ is asserted if the evidence does not hold. Other things being equal, lack of evidence for the presence of an object at a given time in a given space may be used to deduce absence of the object only if it is known to exist, and that it can exist only in these two states. It is machine-implemented by electronic two-position on (1) or off (0) switch for digital computing and data processing. Such assumptions form the basis of Boolean algebra, and are also inherent in rules of manipulation of mathematical objects that differ on the basis of single criteria. 


\subsection{Binary Logic Is Not Reversible}

Another serious limitation of binary logic is that its operators (connectives) AND \& OR are not reversible. In the truth-table for the proposition $\mathrm{z}=\mathrm{x}$ AND $\mathrm{y}$ (below), the truth value for $\mathrm{z}$ (in the first column) is deduced from the truth values of $\mathrm{x}$ and $\mathrm{y}: \mathrm{z}$ is 1 if both $\mathrm{x}$ and $\mathrm{y}$ are 1 , and $\mathrm{z}$ is 0 for the other three sets of values for $\mathrm{x}$ AND $y$. However, it is not possible to re-generate the truth values of $x$ (second column) from the values for $y$ and $z$ in the first column, nor is it possible to obtain values of $y$ (third column) from the values of $z$ and $x$. For example, if both $z$ and $y$ are 0 , the value for $x$ can be 0 or 1 interpreted as doubtful (D). Similarly, if $z=1$ and $\mathrm{y}=0, \mathrm{x}$ is neither 1 nor 0 interpreted as indeterminate $(X) . D$ and $\mathrm{X}$ states for $\mathrm{y}$ are also found in the third column. Output of $\mathrm{X}$ and $\mathrm{D}$ states from inputs of 0 and 1 shows that the operators OR \& AND are not reversible (invertible). Such irreversibility that results in loss of information is due to binary complementation that is also not consistent with the nature of evidence and leads to paradoxes.

Table 2

Truth Tables of Binary Connectives OR \& AND Are Not Reversible

\begin{tabular}{|c|c|c|c|c|c|c|c|c|}
\hline \multicolumn{2}{|c|}{$x O R^{x y} y=$} & \multirow{2}{*}{$\frac{\mathbf{z}}{0}$} & \multicolumn{2}{|c|}{$\mathbf{z} O R^{z y} y=$} & \multirow{2}{*}{$\frac{x}{0}$} & \multicolumn{2}{|c|}{$x O R^{x z} z=$} & \multirow{2}{*}{$\frac{y}{0}$} \\
\hline 0 & 0 & & 0 & 0 & & 0 & 0 & \\
\hline 0 & 1 & 1 & 0 & 1 & $\mathrm{X}$ & 0 & 1 & 1 \\
\hline 1 & 0 & 1 & 1 & 0 & 1 & 1 & 0 & $\mathrm{X}$ \\
\hline 1 & 1 & 1 & 1 & 1 & $\mathrm{D}$ & 1 & 1 & $\mathrm{D}$ \\
\hline \multicolumn{2}{|c|}{$x A N D^{x y} y=$} & $z$ & \multicolumn{2}{|c|}{$\mathbf{z} A N D^{z y} y=$} & $x$ & \multicolumn{2}{|c|}{$x A N D^{x z} z=$} & $y$ \\
\hline 0 & 0 & 0 & 0 & 0 & $\mathrm{D}$ & 0 & 0 & $\mathrm{D}$ \\
\hline 0 & 1 & 0 & 0 & 1 & 0 & 0 & 1 & $\mathrm{X}$ \\
\hline 1 & 0 & 0 & 1 & 0 & $\mathrm{X}$ & 1 & 0 & 0 \\
\hline 1 & 1 & 1 & 1 & 1 & 1 & 1 & 1 & 1 \\
\hline
\end{tabular}

\subsection{Non-existents and Non-issues}

Assumption of complementation of binary logic permits deduction of not-true as false, and vice versa (Suppes 1957). It is self-reference of true or false on the basis of single criteria for truth. It often violates conservation of the information content of a proposition resulting in paradoxical inferences as well as contradictions of omniscience (information), omnipresent (space), omnipotent (energy), and perpetual motion machines. As is common in the public discourse, such self-referential binary arguments with string of negations invariably take the form of your word against my word. Omniscience by self-reference has perplexed thinkers for centuries and its illogic (ku-tark) has been used since ancient times to create impasse (Matilal 1998). President Bush and his senior officials in support of Iraq War in 2001 argued that Saddam Hussein has Weapons of Mass Destruction (WMD) because there is no evidence that he does not have such weapons! It is a template for words for mass deception (WMD) of believers. As used for existence of God: if God did not create the world, then who did. The ultimate cost of this myth (mithya) reasoned and sold to public with a single assertion or criteria (ekant) will cost $99 \%$ of the humanity well over 500 trillion in dollar terms alone. Illogic with fallacious reasoning is now a norm of public discourse. Illogic with fallacious binary reasoning with single criteria is now a norm of public discourse. As religions did in the past, governments and businesses now use fear of omnipresence (spying) and omnipotence (law and security) to subjugate subjects to support the State. It is perpetuated with sound bites 
ritually catered by media to perpetuate ignorance in the name of news and information. A compilation of such methods and purpose would make informative and entertaining reading.

Disconnect between belief and behavior is far and wide. Being wrong is different than being ignorant (Firestein 2012). There is nothing wrong about being wrong, but everything is wrong about staying wrong. Fear and faith added to the mix rob ability to reason. Use of wedge- or non-issues is part of public discourse in virtually all spheres dominated by institutional omniscience: Gloss over the mistakes as if never happened, or deny ever being wrong, keep faithful guessing with inconsistencies and contradictions backed up with words of moral high ground. Wide ranging studies show that religion or faith has no influence on behaviors even among the believers. Systematic study with suitable controls also shows that prayer has no benefit for the recovery of cardiac patients (Benson and coauthors 2005). It is also interesting that about two thirds of the US population describe themselves as the believers, the same proportion as in the US prison population. Also, about two thirds of the US population describe themselves as the believers, the same proportion as in the US prison population.

\subsection{Inference as the Basis for a Theory of Mind}

Religious philosophers maintain that mind-as-machine does not account for human consciousness and will. They are right in the sense that mind is not a machine for binary deduction, and there is no meaningful theory for the diverse functions of mind that integrate functions of organs of neurosensory and neuromuscular system. A suitably developed and trained mind receives external and internal sense inputs to interpret, store, and recall mental images of experiences. Such images are for example used for decision-making, fight-or-flight response, or language communication. Such images are probably also useful for successful survival strategies because they provide for ways to deal with incomplete information and take advantage of feedback and future inputs. Such attributes are however not unique to the humans or even to primates.

As a step towards a theory of mind, the Saptbhangi syllogism could serve as a basic theorem to map the range of inferences consistent with available inputs. The $3 \times 8$ matrix is possibly the smallest unit required to implement a conditional logic gate to choose among the eight possible inference outputs (Jain 2011). It is therefore tempting to consider mind as an engine controlled by such inference gates. Neural networks with inference gates have certain attractive features: They can conditionally and reversibly process multiple and orthogonal inputs in parallel; they can output information not only as $\mathrm{T}$ but also wide ranging $\mathrm{F}, \mathrm{D}$, and $\mathrm{X}$ states to be resolved with additional information; binary deduction is a limiting case in the logic space of orthogonal input but without the limitations of the classical binary gates. Such logic circuits with reversible inference gates are well suited for real time formation and interpretation of images that may persist until affirmed, confirmed, falsified, and ruled out with additional inputs, and also to reconfigure the remaining states for modified output. This is possible because parts of neural circuits remain active for seconds and minutes, where as individual signals last few milliseconds.

Algebraic manipulation of vectors and matrices is isomorphous with states in logic circuits. It allows for inference gates to assemble and dis-assemble the coded image for continuous modification and processing. It is therefore tempting to consider that orthogonal parts of the repertoires of mental images as input vectors could mediate neurosensory functions such as recognition, association, learning, memory, recall, and response. Such a system could also interpret incomplete information and judge its suitability for a response, or wait for additional inputs. 
Mental chatter is hallmark of active mind. Such fleeting awareness is neither interpretable nor verifiable. Momentary mental images persist and cohere as in dreams, hallucinations, visions, and other states often associated with anxiety, hunger, thirst, drugs, sickness, and trauma. Only a magic bag of oracle can take in anything and dispense anything, or make sense out of any experience. However, it cannot be denied that some fleeting experiences do provide occasional glimmer of insights. Like miracles such insights cannot be relied upon for a business model. Ancient literature from all parts of world has numerous assertions of divine insights. Writers and artists have given tantalizing accounts of spontaneous insights obtained after long periods of gestation, meditation, and contemplation. Most of these remain riddles for the lack of incremental understanding that can be reliably used and reused by many (Hook 2002). Over the centuries, mathematicians have jotted down conjectures without explanations or proofs. Some of these intellectual challenges have been proven to be correct. Those of Ramanujam are attributed by him to his family goddess. He lacked formal training to formulate his thoughts in a form that others could understand. Not to undermine the significance and importance of spontaneous ideas, ideas are dime a dozen unless interpreted, verified, made understandable and practicable. Actuality of machines sketched in the Codex of Leonardo da Vinchi was not realized during his life time. Feasibility of some of these was shown by others with the help of technologies invented centuries later. Another remarkable feature of Leonardo's contraptions is their modular design, where the smallest parts are assembled into a functional module that is used in different machines that do different things. Such modular designs have changed the very nature of technological innovation and manufacturing. For example the user-friendly electronic gadgets have thousands of layers of such interconnected modules that work seamlessly and reliably even in the hands of novices.

\section{Here to Where?}

Perception of the world as it is shapes what it ought to be intermingled with subjective desires. In such considerations, self-reference leads to paradoxes, whereas successful behaviors do not contradict reality. With such convictions, methods and products of science have certainly changed the quality of life for most humans. Generalizations of science as such are not perceived by most as adequate guide for personal behaviors and judgments (Wolpert 1993), presumably because of uncertainties about what one knows in real time, and if it is all that is needed to know about the way world works. It does not mean that one should resort to fairy tales and fictions of make-belief and ad hoc unconstrained by the logic of reality. Another option is to let conscience guide "ought" though remaining uncertainties of "is" explored by trial and error. Desires and wishes may dictate choices (Iyengar 2010; Schwartz 2004), and behaviors may seek actions that avoid unpleasant consequences. Individuals also cherish freedom to explore frontiers (Hook 2002), where desire to be architect of own identity and exceptionalism provides meaning, purpose, and direction (Jain 1998) even if it means making fool of oneself (Laham 2012). Irrelevant ideas and practices disappear in the heap of the past, yet for some reason many continue to fall prey to omniscience in moments of weakness. Is it ignorance? Or is it the limitation of "is" that encourages subjective attempt to sculpt "ought" even if it is irrational? No matter what, individual freedom relegates "ought" for desires of subjective self to a chaotic marketplace for choices one makes and bear consequences. With the caveat of buyer be beware, choices become actions, actions become habits, and habits become our character. Crux of the Mahaveer's insight that forms the basis of Jain atheism is that the quality of perceptions evolved through these stages of personal growth shapes identity of individuals. 


\section{Works Cited}

Armstrong, K. History of God: The 4000 Year Quest of Judaism, Christianity and Islam. New York: Knopf, 1993.

Arnold, E. Buddh Charit with Mahabhinish-Kraman by Ashvaghosh (ca. 200 AD): Light of Asia in English. Boston: J. R. Osgood \& Co., 1885.

Benson, H. and coauthors. "Study of the Therapeutic Effect of Intercessory Prayer in Cardiac Bypass Patients, with Editorial on p. 762-764.” American Heart Journal. 2005. 934-43.

Bhandari, C. R. Bhagvan Mahaveer. Bhanpura: Mahaveer Granth Prakash Mandir, 1982.

---. Lord Mahavira: Great Reformer and Architect of Modern Society. New Delhi: M\&P Consultancy, 2001.

Bhattacharya, N. N. Jain Philosophy: Historical Outline. New Delhi: Munshiram Manoharlal Publishers, 1976.

Chand, B. Lord Mahavira. Varanasi: Rajhans Publication, 1948.

Chauthmal. Bhagvan Mahavir. Ratlam: Jainodaya Prakashan, 1942.

Dasgupta, S. N. A History of Indian Philosophy. Cambridge: Cambridge University Press, 1922. Reprinted in 1975 by Motilal Banarasidas, Dehli.

Dawkins, R. The God Delusion. New York: Houghton-Mifflin Co., 2006.

De Waal, F. The Bonobo and the Atheist: In Search of Humanism among Primates. New York: W. W. Norton, 2013.

Diamond, J. The Guns, Germs and Steel: The Fates of Human Societies. New York: W. W. Norton, 1997.

Divakar, S. Tirthankar. 1970. Available on Jainlibrary.org.

Firestein, S. Ignorance: How It Drives Science. New York: Oxford University Press, 2012.

Gandhi, M. K. My Experiements with Truth: Autobiography. Ahmedabad: Navjeevan Publishing House, 1942.

Hart, M. H. The 100: A Ranking of the Most Influential Persons in History. New York: Citadel Press, Kensington Pub. Corp, 1972.

Hastimal. Jain Dharm Ka Maulik Itihas. Jaipur: Jain Itihas Samitee, 1971.

Hastings, J. "Hermann Jacobi on Jain Atheism." Encyclopedia of Religion and Ethics 2 (1910): 186-7. $<\mathrm{http}$ ///archive.org/details/encyclopaediaindexhastuoft>.

Hedges, C. War Is Force that Gives Us Meaning. New York: Public Affairs, 2002.

Hemchandr(a). 1088-1172. Praman Mimansa, Anuyog(a) Vyavacched Dvatrimsika. The appendix of his much larger work Trishasti Salaka Purush Charit (Ed. Hermann Jacobi. Calcutta: Asiatic Society. 2nd ed. 1932) has been published as The Lives of the Jain Elder (English translation by R. C. C. Fynes). In this work Hemchandra describes events from the time of Mahaveer to some 250 years later. In this work for the lay public he builds on the events that came to him from the Shvetamber tradition.

Hiraiynna, M. Outlines of Indian Philosophy. London: George Allen \& Unwin Ltd., 1921.

---. Outlines of Indian Philosophy. London: George Allen \& Unwin Ltd., 1932.

Hook, E. B. "Prematurity in Scientific Discovery: On Resistance and Neglect." Berkeley: University of California Press, 2002. 378.

Hume, D. Treatise of Human Nature. New York: Penguin, 1777. Reprint, 1986.

Iyengar, S. The Art of Choosing. London: Little Brown, 2010.

Jain, D. K. “Sammai Sutt of Siddhsen Divakar.” New Delhi: Bhartiya Gyanpeeth, 2003. 160.

Jain, H. L. "Bhagvan Pushpadant and Pujypad Swami." Jain Siddhant Bhaskar March (1938): 216-24.

---. "Shatkhandagam of Pushpadant and Bhutbali with Dhavala of Veersen." 16 volumes. Amraoti: Jain Sahitya Uddharak Fund, 1939a. 410.

---. "Veer Jinind Chariu of Pushpadant.” New Delhi: Bhariya Gyanpeeth, 1974a. 212.

---. "Veer Vardhman Charit of Sakalkirti." New Delhi: Bhariya Gyanpeeth, 1974b. 255.

Jain, J. L. "Apt Mmansa of Samantbhadra (ca. 300 AD) and Praman Praikcha of Vidyanand (ca. 1000 AD)." Bombay: Sanatan Jain Granthmala, 1914. 80.

Jain, K. C. Lord Mahavira and His Times. New Delhi: Motilal Banarasidas, 1974c.

Jain, K. P. Mahaveer and Buddha. Surat: M. K. Kapadia, 1948.

---. Bhagvan Mahaveer. Delhi: Digambar Jain Publishing, 1951.

Jain, M. K. Akalank: Laghistrayam, Nyay Vinishchaya, Praman Sangrah. Ahmedabad: Singhi Jain Granthmala, $1939 \mathrm{~b}$.

---. Nyay Vinashchay Vivarnam of Akalank (650 AD) with Commentary by Vadiraj Suri. Varanasi: Gyanpith, 1944.

---. Granth Traya of Aklank (ca. 750 AD). 1970. 
---. Tatvarthvartik of Akalank. New Dehli: Bhartiya Gyanpeeth, 1982. 429.

---. "Greed and Grab: Many Are Called yet Few Are Chosen.” Quarterly Review of Biology 73 (1998): 329-32.

---. Nyay Sutr of Gautam. Washington DC: Hira-Pub.org/Nay, 2000a.

---. Shad Darm Samucchay of Haribhadra (ca 550 AD) with Tark Rasya Dipika of Gunratn (1435) and Other Commentaries. New Delhi: Bhartiya Gyanpeeth, 2000b. 536.

---. Shad Darshan Samucchaya of Hari Bhadra (ca. 600 AD) with Tark Rahasya Dipika of Gun Ratn (ca. 1430 AD). New Delhi: Bhartiya Gyanpeeth, 2000c. 536.

---. "Human Natures: Genes, Cultures, and the Human Prospect (book review)." Quarterly Review of Biology 76 (2001a): 345-6.

---. Nyay Avtar (Nyayavatara) of Siddhsen Divakar (ca 400 AD). Washington DC: Hira-Pub.org, 2001 b.

---. "Logic of Evidence Based Inference Propositions." Current Science 100 (2011): 1663-72.

Jain, R. R. Vaddhaman Chariu. New Delhi: Bhartiya Gyanpeeth, 1975. 358.

Jha, G. Nyay Sutr of Gautam (550 BC) and Nyay Bhasya of Vatsyayan (ca. 400 AD). Poona: Oriental Book Agency, 1939. 356.

Johnson, H. M. Trishashi Shalaka Purush of Hemchandra I-VI. Baroda: Oriental Institute, 1951.

Jung, C. G. Man and His Symbols. New York: Doubleday, 1955.

Kasliwal, U. L. Bhadrbahu Charit of Ratnnandi (ca. 1000 AD). Varanasi: Bharati Bhavan, 1912.

Kondey, M. C. Tatvarth Shlokvartik of Akalank with commentary by Vidyanand I-VI. Sholapur: Vardhman Shastri Press, 1949.

Laham, S. M. The Science of Sin: The Psychology of the Seven Deadlies and Why They Are So Good for You. New York: Three Rivers Press, 2012.

Lalwani, G. and R. K. Begani. Trishashti Shalaka Purush of Hemchandra I-V. Jaipur: Prakratbarati Academy, 1975.

---. Jainthology. Calcutta: Jain Bhavan, 1991.

---. Jainism in India. Varanasi: Parshvnath Vidyapeeth, 1997.

Mahapragya. Rishabh aur Mahaveer. Ladnun: Jain Vishva Bharati, 2002.

Matilal, B. K. The Character of Logic in India. Albany: State University of New York Press, 1998.

Moore, M. Stupid White Man. New York: Eegan Books, Harper Collins, 2004.

Mukhtar, J. K. Swami Samantbhadra. Bombay: Jain Granth Karyalaya, 1925.

---. Sammati Sutr of Siddhsen Divakar. Delhi: Veer Seva Mandir, 1965. 61.

---. Apt Mimansa or Devagam of Samantbhadra (ca. 300 AD). Delhi: Veer Seva Mandir, 1967. 119.

---. Yukti-Anushashan of Samantbhadra (ca. 200 AD) with Commentary by Vidyanand (1000 AD). Sholapur: Manikchandra Granthmala, 1977. 187.

Mukhtar, J. K. and P. Shastri. Samadhitantr of Pujyapad with Commentary by Prabhachandra. Delhi: Veer Seva Mandir, 1965. 96.

Muni, G. Mahaveer: 1000 Updesh (Quotes). Udaipur: Amar Jain Sashitya Sansthan, 1973.

---. Indrabhuti Gautam: Ek Anusheelan (Hindi). Udaipur (India): Shree Amar Jain Sahitya Sansthan, 1990.

Pualos, J. A. Irreligion: A Mathematician Explains Why the Arguments for God Just Don't Add up. 2008.

Ramachandran, G. N. Report 79 on Mathematical Philosophy (Vol. IX in Nay Section of This Site as: The Higher Order Boolian Algebra for Syad Nay). Bangalore: Indian Institute of Science. 1979.

--- "Syad-Nyaya System-A New Formulation of Sentential Logic and Its Isomorphism with Boolian Algebra of Genus 2." Current Science 51 (1982): 625-36.

---. "Vector-Matrix Representation of Boolian Algebras and Application to Extended Predicate Logic (Part I \& II)." Current Science 52 (1983): 292-302; 335-41.

Rogers, J. M. and M. K. Jain. "Inference and Successful Behavior.” Quarterly Rev. Biol. 68 (1993): 387-97.

Roy, A. K. A History of the Jainas. New Delhi: Gitanjali Publishing House, 1984.

Saha, S. B. Shatkhandagam of Pushpadant and Bhutbali (ca. 35 AD) with Introduction by H. L. Jain. Faltan: Jain Jinvani Jeernodhhar Sanstha, 1965. 840.

Sanghvi, S. L. The Four Tirthankars. Varanasi: Prshvanath Vidyashram, 1989.

Sanghvi, S. L. and B. D. Doshi. Sammati Tark Prakaran (in 5 Parts) of Siddhsen Divakar. Ahmadabad: Gujrat Puratatva Mandir, 1923.

---. Sammati Tark of Siddhsen Divakar (500 AD). Bomaby: Shri Jain Shvetambar Education Board, 1939.

Schwartz, B. The Paradox of Choice: Why More Is Less. New York: ECCO, 2004.

Shah, N. J. Apt Mimansa of Samantbhadra (200 AD) and Ashtsati of Akalank (700 AD). Ahamdabad: Sanskrit-Sanskriti Granthmala, 1970. 
Shastri, N. Bhagvan Mahaveer aur Unki Archarya Parampara I-IV. SS Chani Granthmala, 1980.

Shastri, Y. S. Traverses on Less Trodden Path of Indian Philosophy and Religion. Ahmedabad: L. D. Institute of Indology, 1991. Suali, L. "Shad Darshan Samucchay of Hirabhardra (ca. 500) with Tark Rahasya of Gunratn (ca. 1435)." Available in Vol. VIII in the Nay Section on this site, Chaukhanbha Sanskrit Series 95 (1905): 91. Varanasi: Chawkhambha Publishers.

Suppes, P. Introduction to Logic. Princeton: D. Van Nostrand Co., 1957.

Suri, G. Mahaveer Charit in Prakrit. Bombay: D. L. Jain Pustakoddhar Series 75, 1929.

Suri, H. ca. 500. "Shad Darshan Samucchay (Saddarshansamucchaya) with Commentary by Manibhadra (ca. 1095)." Available in Vol. VIII in the Nay Section on this site. Varanasi: Chawkhambha Publishers, 1905.

Suri, V. D. Anuyoga Vyavacched Dvatrimska of Hamchandra (1050 AD) Syadvad Manjari of Mallisen (1300 AD). Banaras: Yashovijay Granthamala, 1910.

Tatia, N. That Which Is (Tatvarth Sutr of Umaswami ca 200 AD). San Francisco: Harper Collins Publ., 1994.

Thomas, F. W. Anuyoga Vyavacched Dvatrimska of Hamchandra (1050 AD) Syadvad Manjari of Mallisen (1300 AD). Motilal Delhi: Banarsi Das, 1968. 176.

Upadhye, A. N. Brahat Katha Kosh of Harishen. Bombay: Bhartiya Vidya Bhavan, 1943. 402.

Vidyabhusan, S. C. A History of Indian Logic. Varanasi: Motilal Banarasi Dass, 1970.

---. History of the Mediaeval School of Indian Logic. Reprint of the 1909 edition. New Delhi: Oriental Books Reprint Corporation, 1977.

---. Nyayavatar of Siddhsen Divakar (500 AD). New Delhi: Nag Publishers, 1984. 36.

Wolpert, L. The Unnatural Nature of Science. Cambridge: Harvard University Press, 1993. 